\title{
DIAGNOSTIC IMPORTANCE OF SPONTANEOUS PATHOLOGICAL EYE MOVEMENT
}

\author{
Eiji Sakata, Ru-Pei Lee and Akihiko Imura
}

\section{INTRODUCTION}

The purpose of the vestibular test performed by us otologists is to examine the following aspects, as it is also stated by Frenzel. ${ }^{8}$

First: In the case of otitis media, whether is there any complication in the inner ear or not?

Second: Whether is the feeling of vertigo complained by the patient due to the inner ear dysfunction, as it is the case in Ménière's disease?

Third: Is there any possibility that the tinnitus and deafness could be due to the acoustic neurinoma?

Fourth: Is the impaired equilibrium due to a certain disorder of the central nervous system?, and, if so, its localization and its side?

The vestibular system forms a complex network in the brain stem after it enters there from the labyrinth through the VIIIth cranial nerve, and keeps a close relation with the brain stem, cerebellum, ... etc.

When we analyze vertigo or impaired equilibrium, the central nervous system cannot be left out of consideration because of its anatomical and physiological relation to the vestibular system.

As it is well known, there exist a variety of neurological test methods ranging from a fundamental and routine method using quite simple apparatus to a supplementary diagnostic method supported by various huge and expensive appliances. But, particularly in recent years, there exists a trend that the mechanized diagnostic means is unreasonably regarded as of too much importance and applied beyond its own range of defense.

In the meaning of looking back the lod principle that it is the fundamental neurologic examination that gives the first as well as the last decision to diagnosis of neurological diseases, we will here confine our theme to the vestibular tests with relation to ocular movement, especially to diagnostic method depending upon the "spontaneous pathological eye movement" which can be routinely applied, ambulatorily or at bed-side, without any complex test apparatus.

We will explain its main points and subject in our view to your criticism.

\section{CLASSIFICATION OF SPONTANEOUS PATHOLOGICAL EYE MOVEMENTS ${ }^{28)}$}

Spontaneous pathological eye movements can be put in order and calssified in two From the Department of Otorhinolaryngology, Juntendo University School of Medicine, Tokyo 
groups. One includes those appearing under the condition of non-fixed vision or without gaze and another includes those apt to occur on visual fixation or gaze.

A. Pathological eye movements without fixation or lateral gaze (behind spectacle)

1. Peripheral-and central-vestibular nystagmus (Spontaneous nystagmus in a wide sense)
a. Spontaneous nystagmus in a narrow sense
b. Positional nystagmus
c. Positioning nystagmus

B. Pathological eye movement under gaze condition

2. Gaze nystagmus (mainly disorders of oculomotor system)
a. Gaze nystagmus with various types
b. Gaze paretic nystagmus
c. Convergence nystagmus
d. Divergence nystagmus
e. Retractory nystagmus
f. Disconjugated nystagmus in various types, etc.

3. Fixation nystagmus (mainly disorders of oculosensory system) Idiopathic congenital nystagmus

(pendular, jerking, pendular-jerking, alternating, latent, etc.)

4. Gaze dysmetric nystagmus (mainly disorders of cerebellum)

5. Non nystagmic pathological spontaneous eye movements
a. Opsoclonus
b. Convergence convulsion
c. Gaze convulsion
d. Lightning eye movement
e. Ocular dysmetria
f. Flutter-like oscillation
g. Conjugate deviation
h. Skew deviation
i. MLF-syndrome

The former, indicated by $\mathrm{A}$, is vestibular nystagmus which occurs as a result of peripheral as well as of central vestibular asymmetry. Spontaneous nystagmus in a narrow sense, positional nystagmus and positioning nystagmus are included in this group. In testing such nystagmus, the patient's eyes are equipped with Frenzel-spectacle to remove the function of visual fixation and thus even a weak degree of nystagmus may occur with ease. This bears an analogy with the Romberg's phenomenon.

The latter, indicated by $\mathbf{B}$, is nystagmus which occurs due to disorders of the central nervous system centering around the brain stem. This used to test nervous paresis and is carried out without equipping spectacle.

Gaze nystagmus, shown in 2, gives rise to as a result of disorders of the oculomotor system and there occur a number of important nystagmus as given here. 
Fixation nystagmus, shown in 3 , on the other hand, is principally due to disorders of the oculosensory system, so-called "idiopathic congenital nystagmus" being its representative form which also includes various types.

Nystagmus due to gaze dysmetry, shown in 4, occurs when cerebellar lesions are present. It appears as a result of impairment of co-ordination of 6 pairs of bilateral ocular muscles, and on lateral and upward or downward gaze occurs an unique type of nystagmus which has a little difference in velocity between a dangling type of the slow phase and the quick phase.

Unusual ocular movements shown in 5 are other than those due to nystagmus, and they are of particular importance because of each in itself indicates the localization of its own lesion.

\section{RELATIONSHIP BETWEEN LOCALIZATION OF THE LESION AND OCULAR MOVEMENT}

1) Mesencephalon (tectal, pretectal)

Opsoclonus, Convergence convulsion,

Gaze convulsion, Lightning eye movement,

Convergence nystagmus, Convergence palsy,

Retractory nystagmus,

Spontaneous vertical nystagmus to the upper palpebra,

Parinaud's sign, Spontaneous horizontal nystagmus,

Horizontal gaze paretic nystagmus, etc.

The subcortical intermediate center for upward gaze exists in the pretectal region of the midbrain. Therefore, when it causes paresis, vertical nystagmus in the upward direction may occur or paralysis of upward gaze may develop. The Perlia nucleus was formerly regarded as the center of convergence, however, it is wrong. The convergence center is also present in this pretectal region of the midbrain. In addition, the center of pupillary accomodation and of horizontal gaze movement is present in the tectum. When this region is affected, a variety of diagnostically important abnormal eye movement may occur, as shown in the table. ${ }^{2,4,10,17,18}$

Figure 1 is one of such cases having ependymoma in the posterio-inferior region of the third ventricle. Both convergence and pupillary accomodation are impaired, but downward gaze function remains intact. In contrast, upward gaze function is completely paralytic and the Parinaud's sign is also visible.

In addition, convergence nystagmus is observed upon frontal visual fixation or convergence wherein both eye-balls simultaneously move in the inner direction, and this is accompanied by retractory nystagmus with sinking of both eye-balls into the inside of the orbita.

Figure 2 is a case of pinealoma which is very small in size. Upward gaze is possible, however, upon frontal visual fixation spontaneous vertical nystagmus to the upper palpebra is already observed. This is detected as paresis of upward gaze in the early stage, but when it further advances to the state of complete paralysis it gives rise to the Parinaud's 


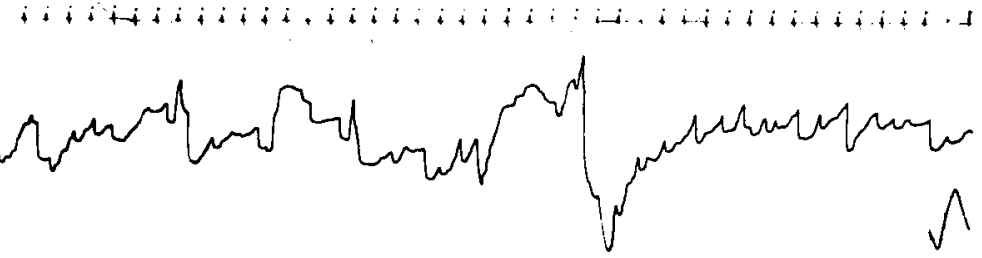

A
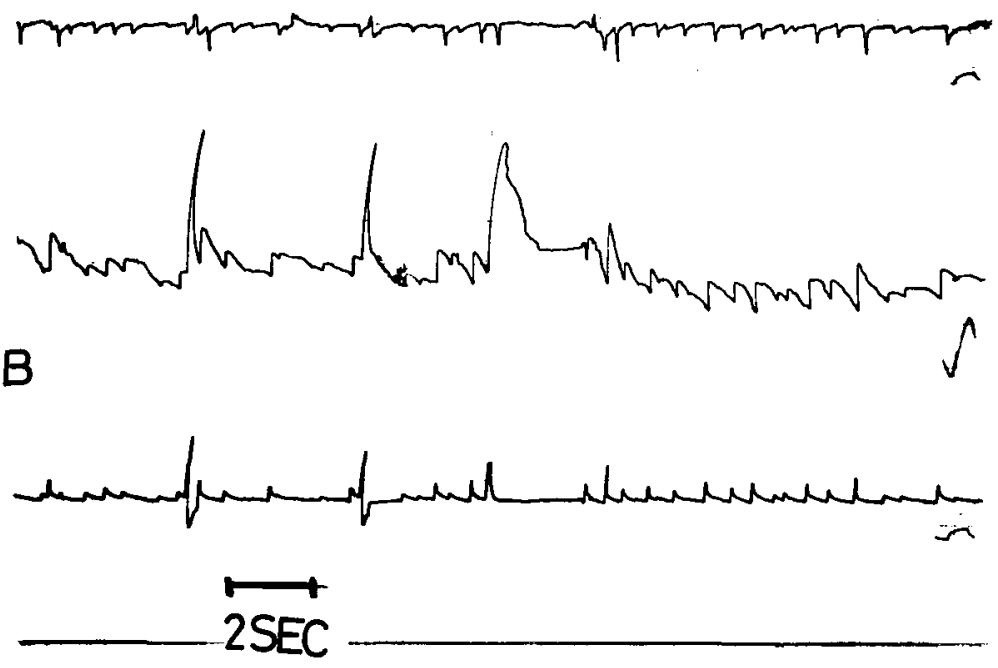

\section{T.T.,44s}

Fig. 1: T.T., 44 1 , ependymoma in the postero-inferior region of the third ventricle. Convergence nystagmus recorded by ENG. From the upper 1 st and 2 nd curves were led from the right eye-ball $(A)$, and 3 rd and 4 th curves the left one $(B)$.

The first and third curves show in eye-ball deviation $(\tau=3)$, and the second and fourth. eye speed of slow phase of nystagmus $(\tau=0.015)$. Horizontal recording.
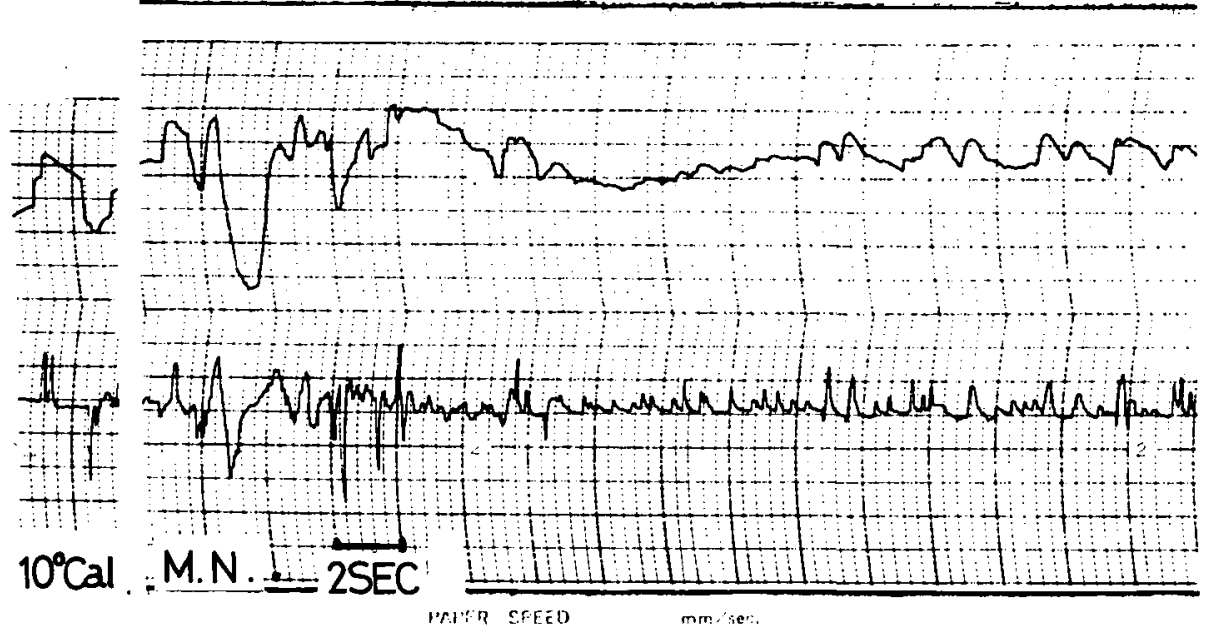

Fig. 2: M.N., 37 \&. Pinealoma.

ENG of spontaneous vertical nystagmus to the upper palpebra by vertical recording.

Equilibrium Res Suppl. 2 
$\operatorname{sign.}^{28}$

As mentioned above, at a mere glance of nystagmus convergence, nystagmus retractorius, or spontaneous vertical nystagmus directed to the upper palpebra, disorders of the third ventricle or the upper brain stem should be considered. The pretectal region is regarded as responsible for such signs.

Gaze convulsion is recognized on lateral, upward and downward gaze, the eye-balls appear swing violently right and left.

Figure 3 is similar to the gaze convulsion, but referred to as lightning eye movement. On mere vacant frontal fixation the eye-balls at times swing like a flash of lightning for a short moment. ${ }^{2,21}$ This sign is said to be due to disorders of the midbrain tectum, and often observed in cases of, for instance, multiple sclerosis, arteriosclerotic parkinsonism, tumor, vascular lesion, anticonvulsive drug intoxication etc. Opsoclonus, gaze convulsion and lightning eye movement indicate the lesion of midbrain due to myoclonic ataxia. ${ }^{21}$

2) Pons (dorsal, paramedian)

Divergence nystagmus,

Horizontal gaze paretic nystagmus,

Coniugated deviation to the opposite side,

Spontaneous vertical nystagmus to the lower palpebra.

The subcortical center of horizontal gaze movement exists in the paramedian pontine reticular formation (PPRF) as it does in the midbrain. Hence, any disorder of PPRF

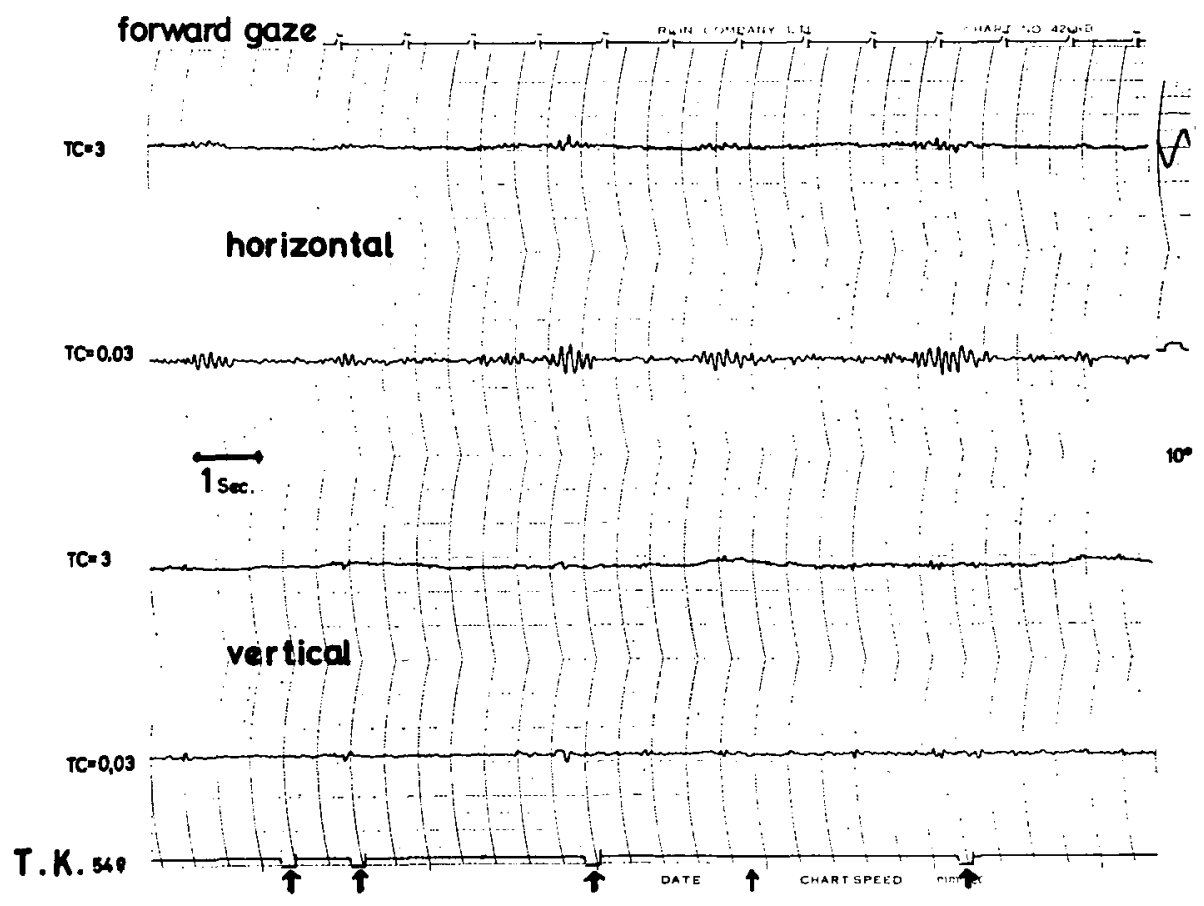

Fig. 3: T.K., 54 오, anti-convulsant intoxication. Note, the "lightning eye movement" seen in the horizontal recording. 


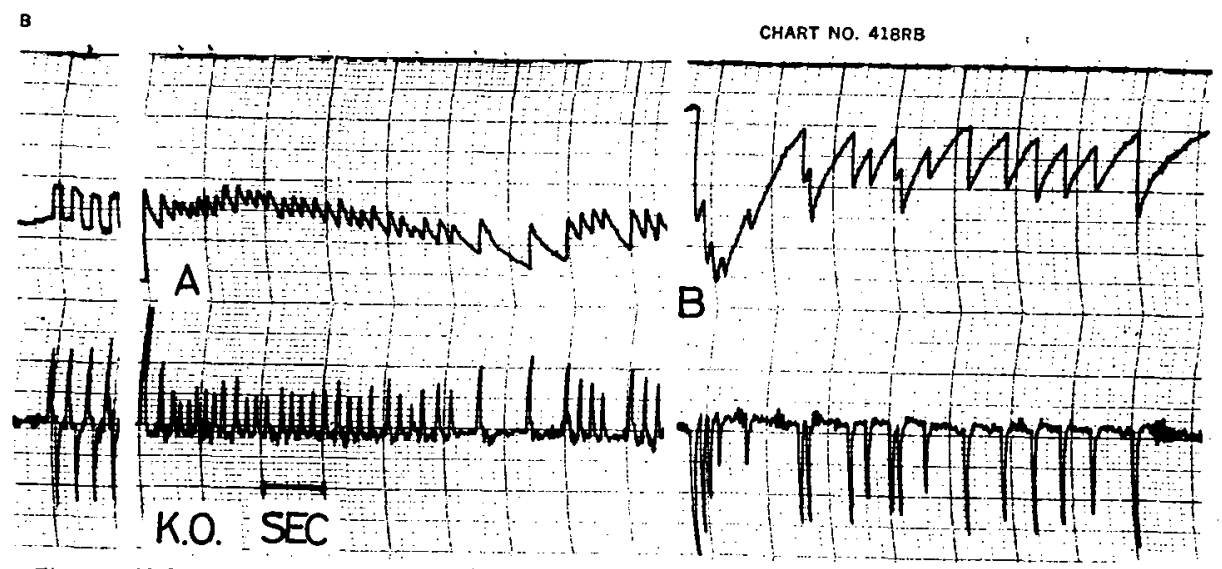

Fig. 4: K.Q., 35우, acoustic neurinoma 1t.

So-called "Bruns-Cushing-nystagmus'.

- A: right lateral gaze

$B$ : left lateral gaze

may result in appearance of various types of horizontal paretic nystagmus or paralysis of the lateral gaze. Hypothesis has been advanced that the center of divergence may also be present in this PPRF. ${ }^{1,14}$

If this region is affected, the conjugate deviation appears to the intact side. ${ }^{28}$

Figure 4 is a case with acoustic neurinoma. On frontal visual fixation, right-directed horizontal nystagmus rapidly appears. On right lateral gaze it becomes to high-frequency nystagmus, but on left lateral gaze slow-paced large and paretic nystagmus is observed. This is referred to as Bruns-Cushing-nystagmus, ${ }^{29}$ and at its mere glance it may fairly be asserted that the brain stem, in particular the pontine region is affected and that its lesion exists on the side to which such paretic nystagmus is directed.

Conjugate deviation of pontine origin directs to opposite side. In addition, it is accompanied by peripheral paralysis of the facial nerve.

This deviation forms a contrast to that due to the internal capsular disorder in which the deviation is directed to the affected side, and is due to oculomotor decussation existing between nuclei of the third and fourth cranial nerves. ${ }^{14}$

3) Medulla

Opsoclonus,

Pure rotating or horizontal spontaneous nystagmus,

Spontaneous vertical downward-beating nystagmus to the lower palpebra,

Irregular mixed nystagmus.

There are four vestibular nuclei in the medulla oblongata. Together with the labyrinth and cerebellar hemispheres, here is the origin of a these nuclei. This nystagmus, either rotatory or horizontal, is always pure and never occur in a mixed form.

Figure 5 is a case of basilar impression and Arnold-Chiarii-malformation. In opposition to the nystagmus observed in the previous case with midbrain disorder, vertical spontaneous nystagmus directed to the olwer palpebra is visible upon frontal visual fixation. 


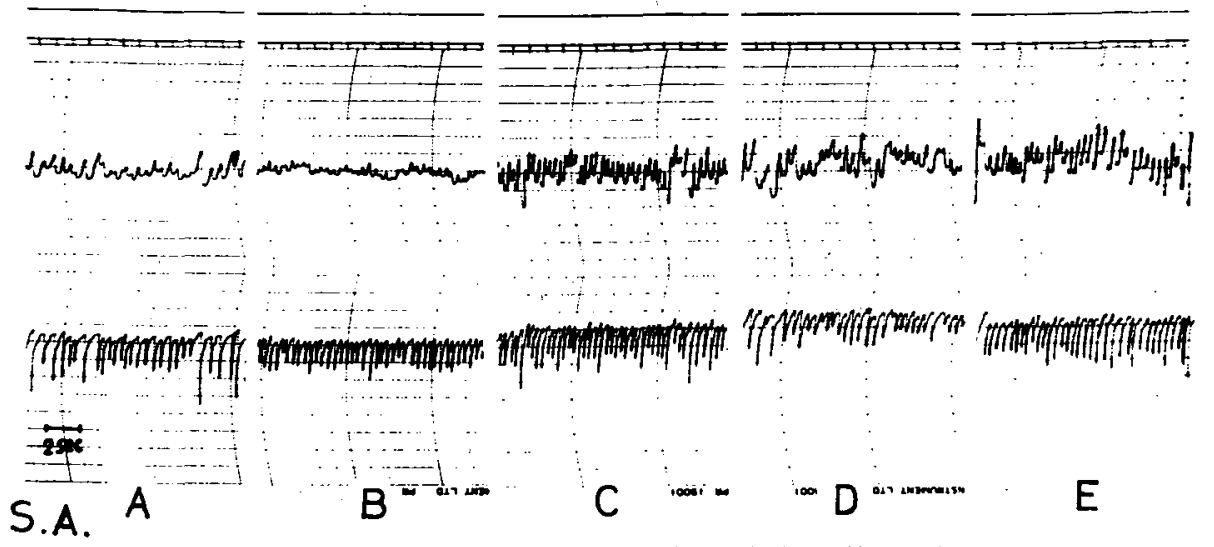

Fig. 5: S.A., 47 우, basilar impression and Arnold-Chiarii-malformation. Spontaneous vertical nystagmus to the lower palpebra by vertical recording.
A: forward fixation
$B$ : right lateral gaze
C: left lateral gaze
D: upward gaze
E: downward gaze

This occurs as a result of paresis of downward gaze. Some investigators have claimed that downward gaze paralysis also occurs due to midbrain lesions, ${ }^{14}$ but we are supporting that the region related to downward gaze may exist in the lower brain stem. However, the verminal portion of the cerebellum, especially the flocculus or paraflocculus may relate, through some forms to the development of this nystagmus. In any way, this type of nystagmus is often seen in cases of disorders in the lower brain stem or in the lower cerebellum, and we hope to take care for further clinical facts in future.

Opsoclonus is seen i.e. in a case of brain stem encephalitis. ${ }^{24}$ This is generally thought to be due to lesions within a triangular portion (connecting three nuclei, the red, dentate and olivary nuclei,) however, according to the autopsy findings a particular attention has been paid to the loss of nerve cells of the olivary nucleus.

4) Dorsal portion of brain stem

MLF-syndrome (unilateral, bilateral)

The dorsal area of the brain stem has long been referred to as a "silent area" and the diagnosis of its minor lesions is sometimes very difficult to establish by means of general neurological examinations. However, it is very "noisy" with respect to eye movement, since the medial longitudinal fasciculus (MLF) is in this area.

The MLF-syndrome is one of such instances. On right lateral gaze, there appear adductor paralysis in the left eye and lateral-directed horizontal nystagmus in the opposite eye. On the contrary, on left lateral gaze, there appear adductor paralysis in the right eye and lateral-directed horizontal nystagmus in the opposite eye. ${ }^{19}$ It is typical of the MLF-syndrome that the function of convergence remains intact.

5) Brain stem in general

We will arrange the almost common findings with respect to general brain stem dis- 
orders. We can cite the various characteristic findings as shown in the table. ${ }^{3,7,16,20,22,28,29}$

Direction-changing spontaneous nystagmus under the various conditions

(eye closed, behind spectacle or in dark room etc.),

Disconjugated nystagmus in various types,

Direction-fixed positional nystagmus,

Direction-changing upward-beating positional nystagmus,

Vertical positional nystagmus in head hanging position,

Vertical positioning nystagmus,

Unrhythmic haunt nystagmus.

Above all, since the brain stem shares the area with the medial longitudinal fasciculus, so-called disocnjugated eye movement is often visible if either is affected.

Among the affected cases of the brain stem there are some cases wherein the direction of nystagmus spontaneously alters according to variation of the conditions. This is also one example of such cases. The horizontal nystagmus directed to the left appeared on frontal visual fixation, but behind spectacle the direction changed to the right.

See-saw nystagmus is one example of cases with disconjugated nystagmus. One eye is rotating and directed upward and the other eye is rotating and directed downward. In general, when the medulla is affected nystagmus which rotates to the direction of the affected side appears, but if MLF is subjected to its influence this nystagmus becomes of see-saw type.

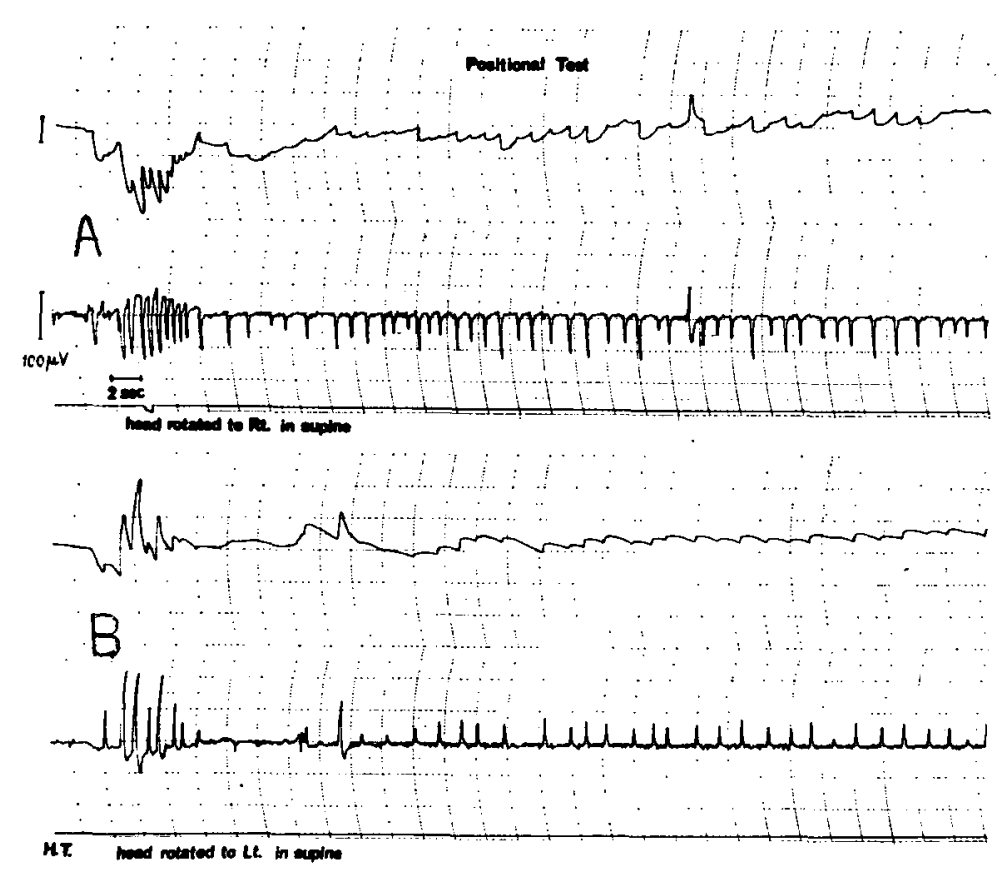

Fig. 6: H.T., $37 \hat{\delta}$, spino-cerebellar degeneration (Marie's type). Direction-changing upward-beating positional nystagmus by horizontal recording.

$A$ : head rotated to right in supine

$B$ : head rotated to left in suqine

Equilibrium Res Suppl. 2 
The next case e.g. lacks spontaneous nystagmus in a narrow sense, but leftward nystagmus first appears on declinging the head to the left side. Even if the head is declined to the opposite side leftward nystagmus still appears. Thus in this case, nystagmus first appears on alternation of the head position and its direction is always the same. This is referred to as "direction-fixed positional nystagmus", which appears when a lesion unilaterally exists in the peripheral vestibulum, brain stem, cerebellum, etc.

Apart from the above case, rightward nystagmus appears on declining the head to the left side and its direction becomes opposite when the head is declined to the right side. In such cases the positional nystagmus is always directed to the above-situated ear. This is called direction changing upward-beating positional nystagmus. This type of nystagmus is seen when the lesions of the subtentorial structures such as the cerebellum and the brain stem affect the central portion of these structures, directly or indirectly. ${ }^{28,29}$
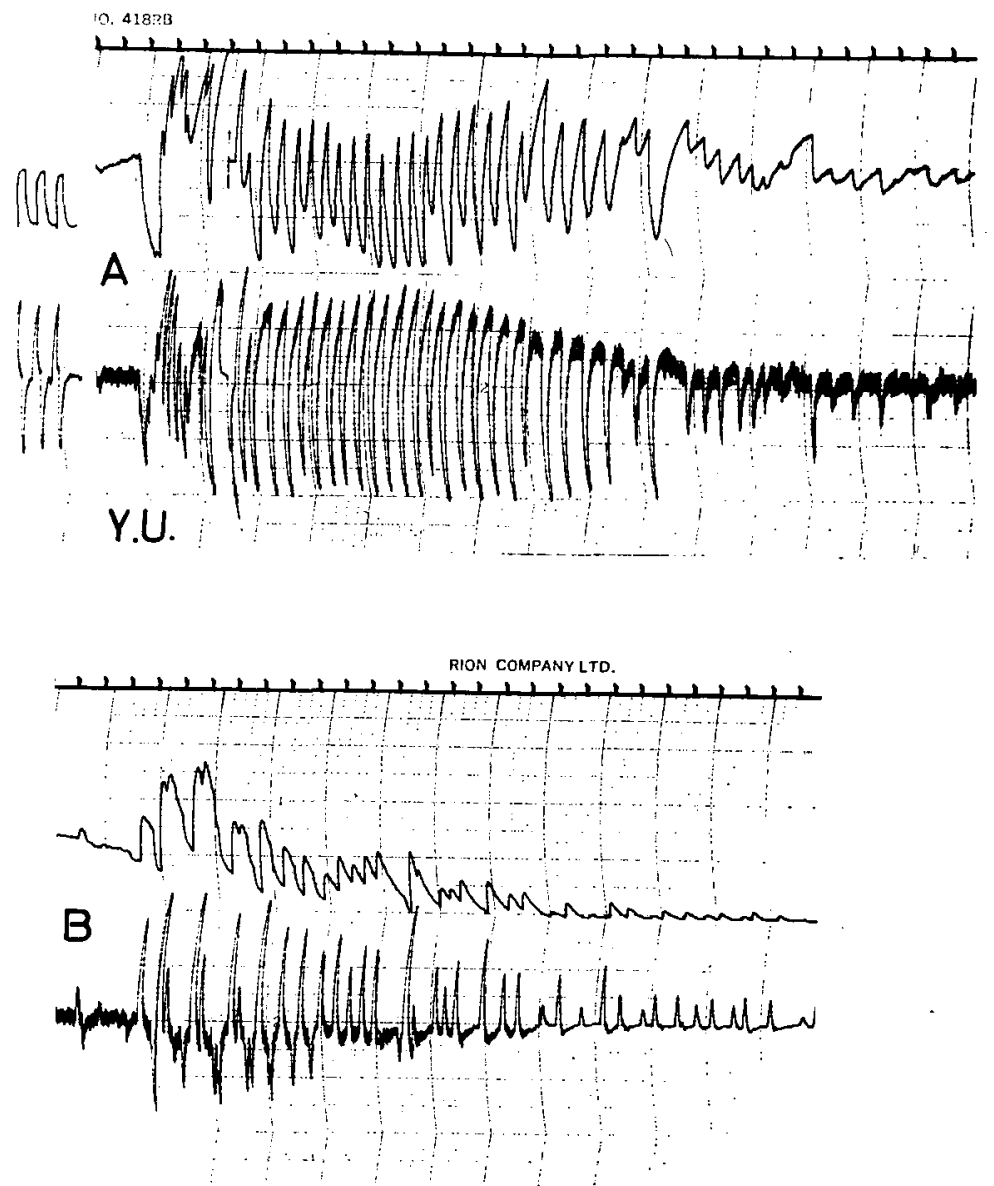

Fig. 7: Y.U.. 42 9, spino-cerebelfar degeneration (Marie's type). Vertical positioning nystagmus by vertical recording. Note, the finding that the direction of nystagmus changes by opposing movement is characteristic of cerebellar atrophy.

A: Supine with head hanging after positioning stimulation

$B$ : Sitting with head straight after positioning stimulation 
In similar cases of subtentorial disorders, vertical nystagmus often appears on mere head position, and this finding is very important in early diagnosis. In such cases the vertigeous attack does not accompany as seen in labyrinthine disorders.

Also in positioning test vertical nystagmus is observed in the extremely early stage. Vertical nystagmus in itself indicates the existence of lesions in the cerebellum or brain stem, and the finding that the direction of nystagmus changes by opposing movement is characteristic of cerebellar atrophy as seen in the Figure $7:^{28,29}$

Now, there is generally a group of nystagmus called "idiopathic congenital nystagmus, ${ }^{5,11,12,13,15,27,32,33}$ and there is of pendular type among this group. The nystagmus like this is of coarsely beating type and easily realized by any body. If we are not well aware of this type of nystagmus, useless tests are apt to be performed under the suspect of brain tumor which often results in putting the patient to economical and physical expense. $^{28}$

It is known nystagmus of jerking type too. Each of these is ataxia appeared only in the eyes, and usually there is no accompaniment of abnormal findings detectable by other tests.

Periodically alternating horizontal nystagmus is called "alternating nystagmus" wherein the direction of spontaneous nystagmus alternates at intervals of about 90 seconds. It is generally presumed that congenital nystagmus may originate from the brain stem, especially the upper brain stem, however, we think that at the same time disorders of the middle portion of the cerebellar vermis should be taken into consideration. ${ }^{30}$

There is nystagmus latent. On covering one eye it turns upward and in another uncovered eye outward-directional nystagmus appears. In the case of this nystagmus the patient is simultaneously conscious of oscillopsia.

6) Hemispheric portion of cerebellum

In the cerebellar hemispnere there is not area to cause spontaneous nystagmus by its own lesions. ${ }^{14}$ In such cases, however, horizontal or rotatory nystagmus almost invariably occurs upon bilateral or upward gaze. Nucleus dentatus also has relation with such a kind of nystagmus. Particularly in tumors, since the intracranial pressure elevates in an early stage and influences upon the cerebellar vermis or brain stem, it becomes dysmetric due to the element of gaze paresis plus dysfunction in coordinate movement of 6 pairs of the ocular muscles. Such nystagmus becomes of rotatory type and is of a peculiar sort. $^{23,24,25,26}$

Gaze dysmetric horizontal or rotating nystagmus,

Direction-fixed positional nystagmus,

Pure rotating positioning nystagmus without vertigeous

sensation, nystagmus latency and decline phenomenon,

Flutter like oscillation, Ocular dysmetria.

In a case with cerebellar tumor, in general, on frontal visual fixation on nystagmus appears, but on bilateral and upward gaze a dangling type of horizontal nystagmus is visible.

Equilibrium Res Suppl. 2 


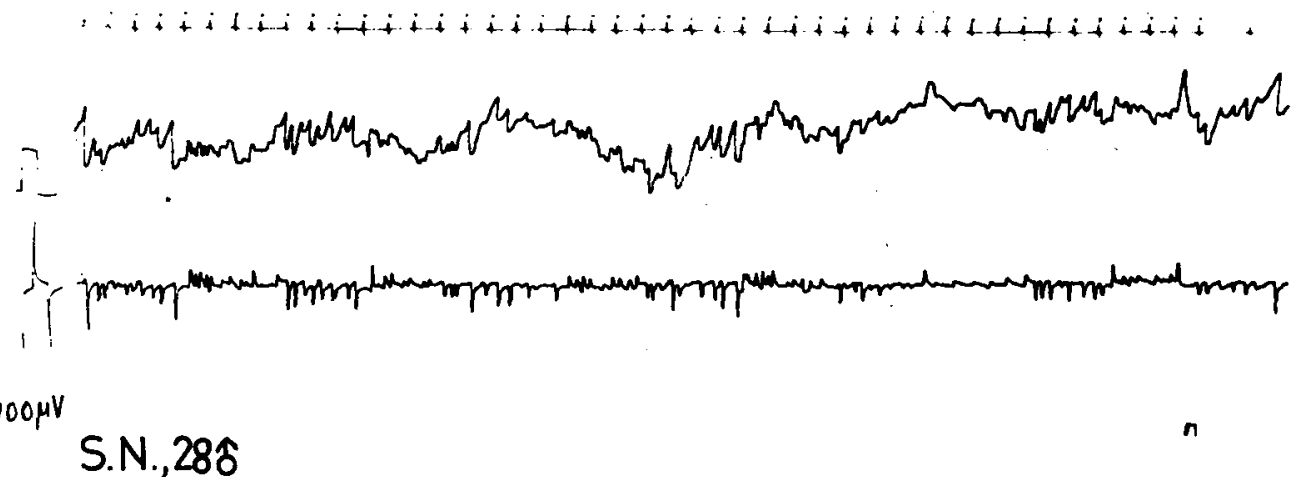

Fig. 8: S.N., 28 , hematoma of verminal portion of cerebellum. "irregular burst of horizontal spontaneous nystagmus".

7) Verminal portion of cerebellum

Of the verminal portion of the cerebellum, the upper and lower vermis have relation with maintenance of the position of one's body or of the state of equilibrium, and particularly the lower vermis genetically constituet the vestibular system and plays a role of inhibitor in this system. In disorders of these areas vertical nystagmus appears, especially in relation to the head position. ${ }^{6,14,30}$

In contrast, the fastigial nuclei in the intermediate portion take part in horizontal visual movements and have influence on reticular formation of the midbrain and pons or on the vestibular nuclei. ${ }^{9}$

Gaze dysmetric nystagmus,

Irregular burst of horizontal spontaneous nystagmus, ${ }^{30}$

Direction-fixed positional nystagmus,

Direction-changing upward-beating positional nystagmus,

Vertical positional nystagmus of head hanging,

Vertical positioning nystagmus with vertigeous

sensation but without decline phenomenon,

Flutter like oscillation, Ocular dysmetria,

Fixation jerk.

Figure 8 is a case of raptured hemangioma in the verminal portion, wherein the direction of nystagmus is changing at short intervals. In this, we reffer to as "irregular burst of horizontal spontaneous eye movement" and regard as the pathognomonis sign of disorders of the fastigial nuclei. ${ }^{30}$

In disorders of bilateral fastigial nuclei or of the lower vermis, vertical nystagmus appears on head hanging which is accompanied by violent feeling of vertigo as seen in labyrinthine disorders. ${ }^{30}$

8) Cerebral hemisphere

In the cortex of the cerebral hemisphere there exists the highest center of eye movement, however, so explicit nystagmus is not visible when the cerebral cortex is involved 
because of a wide dispersal of such center. But when a tumor develops in the parietal lobe or intracranial pressure is elevated, one or two interesting phenomena may occur; that is direction changing, downward-beating positoinal nystagmus. ${ }^{28,29}$

Spontaneous horizontal nystagmus,

Direction-changing downward-beating positional nystagmus,

Conjugated deviation to affected side.

Direction-chainging downward-beating positional nystagmus is often recognized in such cases with parietal labor lesion. Nystagmus is visible in this case differs from that of the previous subtentorial disorders, and occurs to the right on declining the head to the right, and vice versa. In other word, positional nystagmus is always directed to the lower-situated ear.

9) General disorder of CNS.

When a diffuse degeneration develops in the central nervous system or intracranial presure is elevated, nystagmus in the direction of gaze may appear as a result of release from inhibition. Furthermore, when the center of horizontal gaze movement in the midbrain and pons, and lower brain stem are all involved, complete gaze-directional nystagmus may be evoked. ${ }^{28,29}$

Bilateral gaze nystagmus occurs to the right upon right gaze, and to the left upon . left gaze. Both are identical in amplitude and frequency.

On right, left, upward and doward gaze, nystagmus invariably occurs in the respective directions; that is complete gaze direction nystagmus.

10) Labyrinth

We have discuss to now about the relationship between disorders of the central nervous system and nystagmus, however, the nystagmus which appears in disorders of the labyrinth having three semicircular canals and is for the most part of mixed from of horizontal and rotatory types. In general, pure nystagmus cannot be so frequently observed, and it usually appears in a more or less mixed form of these two elements.

Nystagmus of case of acute labyrinthine dysfunction is of a mixed form of both horizontal and rotatory elements. ${ }^{8}$

The intermittent period of Ménière's disease is asymptomatic, however, a mixed form of nystagmus, horizontal and rotatory, may be evoked on declining the head to the affected ear and it may be accompanied by attacks of vertigo.

In labyrinthine disease, it is not so rare that vertigo or nystagmus is of pure rotatory type, but is differs in nature from that due to medullar or cerebellar lesions. ${ }^{29}$

In positioning test, the same pure rotatory nystagmus is evoked, and direction changing nystagmus induced by mutually opposite movements, as having the patient rapidly in the chinning position and then returning to the original position, is the pathognomonic sign of labyrinthine disorders. In addition, it differs from nystagmus of medullar of cerebellar origin with respect to the findings that it has a latency of several seconds and it first beats crescendo and then decrescendo accompanying vertigo. Decrement phenomenon is also visible. ${ }^{9,29}$ 
Horizontal-rotating spontaneous nystagmus,

Direction-fixed positional nystagmus,

Pure rotating positional nystagmus with vertigeous

sensation, nystagmus latency and decline phenomenon,

Pure rotating counter-rolling positioning nystagmus

with vertigeous sensation, nystagmus latency

and decline phenomenon.

In cases of labyrinthitis or labyrinthine syphilis, vertigo or nystagmus may be evoked by putting a slight pressure. This is called "labyrinthine fistula symptom". Nystagmus appearing in this case is of a mixed form, horizontal and rotatory.

\section{CONCLUSION}

In former years certain world-famous scholars have stated every times the matter of the following meaning: "When once we study on nystagmus, we wholly fall in a labyrinth and eventually are at a loss what to do". ${ }^{34}$

But this statement is quite unconstructive. It may be impossible to deny the fact that such a view has been a gross obstacle in the up-to-date development of nystagmology or neurotolgy.

There may be various reasons, however, a great difference may be that while they had approached nystagmus by studying multiple screlosis wherein multiple lesions randomly appear or disappear throughout the central nervous system, we, otologists, approached this problem on the basis of the peripheral labyrinth which has a regular manner to the ocular responses.

We have steadily advanced our study from the labyrinth to the retro-labyrinth, and now we are approaching the central nervous system which could not be accomplished by Frenzel.

The accumulation of valuable clinical case data on the one hand, and the outcomes from various co-works with neurosurgeons and neurologists on the other hand are supposed to give us a powerful assistance and to support our confidence and pride.

\section{ACKNOWLEDGEMENT}

We wish to thank Professor Shozo Kawamura for his unlimited help in this investigation, and also to members of research group of Otoneurology in our University.

\section{REFERENCES}

1) Bender, M.B. and Savitsky, V.: Paralysis of Divergence. Arch. Ophthal. 23: 1046, 1940.

2) Bender, M.B. and Shanzer, S.: Oculomotor Pathways Defined by Electric Stimulation and Lesions in the Brain Stem of Monky. The Oculomotor System, Hoeber, New York, 1964.

3) Bender, M.B.: Oscillopsia. Arch. Neurolog. Piychiat. 13: 204, 1965.

4) Bielshowsky, A.: Symptomatologie der Störungen im Augenbewegungsapparat. BumkeFoersters Handbuch der Neurologie, Vol. 4, Springer, Berlin, 1936.

Equilibrium Res Suppl. 2 
5) BRUNNER, H.: Über die Inversion des experimentellen optokinetischen Nystagmus. Mschr. Ohrenheilk. 55: 574, 1921

6) Fernandez, C. et al.: Experimental observations on postural nystagmus. II. Lesions of nodulus. Ann. Otol. Rhin. \& Laryng. 69: 94-114, 1960.

7) Frederickson, J.M., Schwarz, D.M. and Kornhuber, H.H.: Vestibular Disorders in Fourth Ventricle Lesions. Arch. Otolaryng. (Chicago) 80: 521, 1964.

8) FrenZel, H.H.: Spontan-und Provokations-Nystagmus als Krankheits-symptome. Springer, Berlin-Göttingen-Heidelbrerg, 1955.

9) Hoshino, T.: Beiträge zur Funktion des Kleinhirns beim Kaninchen. Acta oto-laryng. (Stockh.) Suppl. 2: 1, 1921.

10) Jung, R.u. Hasler, R.: The Extrapyramidal Motor System. Handbook of Physiology. Section I: Neurophysiology II, 863. American Physiological Society, Washington, D.G., 1960.

11) Jung, R.u. Kornhuber, H.H.: Results of Electronystagmography in Man: The Value of Optokinetic Vestibular and Spontaneous Nystagmus for Neurologic Diagnosis and Research. The Oculomotor System, Hoeber, New .York, 1964.

12) KomaI, N.: Stereotaktische Operationen zur Behandlung des Nystagmus, der vestibulären Ataxie und der spastischen Muskeltonussteigerung. Neurochirurgia. 10: 19, 1967.

13) Kornhuber, H.H.: Über Begleitschielen und latenten Nystagmus aus neurologischem Sicht. Sitzungsber. Rhein-Westf. Augenarzte, 102 Versamml. Gebr. Zimmermann, Balve i.w., 1960.

14) Kornhuber, H.H.: Physiologie und Klinik des zentralvestibulären Systems. (Stütz-und Blickmotorik), Georg Thieme, Stuttgart (im Druck).

15) Kornhuber, H.H.: Der periodisch alternierende Nystagmus (Nystagmus alternans) und die Enthemmung des vestibulären Systems. Arch. klin. exp. Ohr.-, Nas,-u. Kehlk. Heilk. 131 : 845, 1957.

16) Lorent, de No, R.: Die Labyrinthreflexe auf die Augenmuskeln nebst einseitiger LabyrintExstirpation nebst einer kurzen Angabe über den Nervenmechanismus der vestibulären Augenbewegungen. Mschr. Ohr. hk., Wien, Ohrenheilk. 61: 857, 1066, 1152, 1300, 1927.

17) Magoun, H.W.: Maintenance of the Light Reflex after Destruction of the Superior Colliculus in the Cat. Amer. J. Physiol.

18) Muskens, L.J.J.: Das supravestibuläre System bei den Tieren und beim Menschen, mit besonderer Berücksichtigung der Zwangsstellungen und der Zwangsbewegungen. N.V. NoordHollandsche Witagevermootschappij. Amsterdam, 1934.

19) Nagashima, C. et al.: Syndrome of the median longitudinal fasciculus. Brain and Nerve. 21: 139-154, 1969.

20) Neveling, R.u. POECK, K.: Die Störung der schnellen Nystagmusphase bei Oblongataherd (Wallenberg-Syndrom.) Arch. klin. exp. Ohr.-, Nas.-u. Kehlk. Heilk. 178: 740, 1960.

21) Otsuka, Y. und Stakata, E.: Beiträge zur Diagnostik der sog. "Blitzaugenbewegungen", im Hinblick auf deren Pathophysiologie. (im Druck).

22) Riesco-Mac Chure, J.S. and Stroud, M.H.: Dysrhythmia in Post-caloric Nystagmus: its Clinical Significans. Laryngoscope 70:697, 1960

23) Sakata, E. u.a.: Das neurootologische Studium über die Kleinhirnstörung. Der I. Bericht: Ob die Störung der Kleinhirnhemisphäre durch die Prüfung der Augenbewegung diagnostiziert werden kann? Pract. Otol. (Kyoto) 61: 1642-1658, 1968.

24) Sakata, E.: Das experimentelle Studium über den Spontan-und Provokations-Nystagmus. 
Das Studium I: Das Zerstörungsexperiment der einseitigen Kaninchen-Labyrinth und des Kleinhirns. Jap. Jour. Otol. Tokyo 70: 385-394, 1967.

25) Sakata, E. u.a.: Der Kleinhirntumor und Schwindelanfall, Ménière Krankheit und deren Umkreis, V. Bericht. Pract. Otol. (Kyoto) 62: 1089-1100, 1969.

26) Sakata, E. u.a.: Spontan-und Provokations-Nystagmus. Seine diagnostische Bedeutung bei Gleichgewichtsstörungen mit und ohne Schwindel. HNO (Berl.) 14: 289-298, 1966.

27) Sakata, E.: Pathohistologische Befunde eines sezierten klinischen Falls des periodisch-alternierenden horizontalen Nystagmus (N. alternans), im Druck.

28) SaKaTA, E.: Wie kann man die Gleichgewichtsstörungen durch die Untersuchung des spontanen pathologischen Augenbewegung mit und ohne Leuchtbrille diagnostizieren? Pract. Otol. Kyoto 63: 431-463, 1970.

29) Sakata, E. und Komatsuzaki, A.: Spontan-und Provokations-Nystagmus. Seine diagnostische Bedeutung bei Gleichgweichtsstörungen mit und ohne Schwindel. HNO (Berl.) 14: 289298, 1966.

30) Sakata, E.: Neurotologisches Studium über die Läsion des Kleinhirnwurms. Equilibrium Res. Suppl. 1: 30-48, 1971.

31) Stenger, H.H.: Über Lagerungsnystagmus unter besonderer Berücksichtigung des gegenläufigen transitorischen Provokationsnystagmus bei Lagewechsel in der Sagittalebene. Arch. klin. exp. Ohr.=, Nas.-u. Kehlk, HCilk. 168: 220, 1955.

32) Suzuki, J.: Pendular Nystagmus: its Contribution to the Understanding of Nystagmus Mechanismus. Acta otolaryng. (Stockh.) 53: 381, 1961.

33) Takabayashi, H.: Superior Colliculus. Its Functional Anatomy, Pathophysiology and Clinical Evaluations, Bunkyo-Shoin. Tokyo, 1965.

34) Wartenberg, R.: Diagnostic tests in neurology. A selection for office use. Year Book Publishers, Inc,. Los Ang., 1953.

(Received August 4, 1971) 